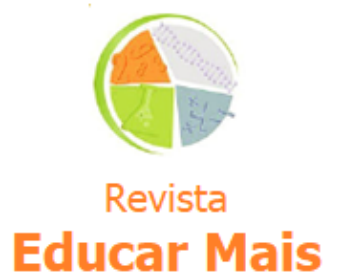

\title{
A formação docente em Ciências Naturais e o papel do professor-tutor: um panorama das ações formativas no estado do Pará
}

\section{Teacher training in Natural Sciences and the role of teacher-tutor: an overview of training actions in the state of Pará, Brazil}

Sebastião Rodrigues-Moura'; Waléria Pereira Monteiro Corrêa; Zenaíde dos Santos Lopes ${ }^{3}$

\section{RESUMO}

O acesso aos cursos superiores no Brasil, principalmente nas licenciaturas, vem ganhando espaço e destaque na modalidade à distância, por aspectos socioeconômicos que são levados em consideração pelos estudantes. Nesse cenário, abordamos nesta pesquisa o cenário formativo no estado do Pará, em especial ao curso de ciências naturais e o papel do professor-tutor, com vistas a analisar os aspectos da formação docente em ciências naturais nas instituições de ensino superior no estado e a atuação do professor-tutor neste processo. Em uma abordagem qualitativa de pesquisa, utilizamos a pesquisa exploratória quanto aos objetivos e de estudo de caso quanto aos procedimentos para que identificássemos indicadores da investigação. Os resultados aportaram-se em duas dimensões: o primeiro discorre sobre o cenário paraense para a formação de professores e em outro argumenta o papel importante do professor-tutor que acompanha o estudante do curso de ciências naturais em todo o processo de ensino-aprendizagem, garantindo e primando pela qualidade nos estudos em espaços virtuais. Portanto, os dados analisados apontam para os indicadores do processo de formação à distância no estado e o destaque do papel do professor-tutor com aspectos de mediação pedagógica.

Palavras-chave: Educação à distância; Cenário formativo; Ciências Naturais; Professor-tutor.

\begin{abstract}
Access to higher education in Brazil, especially in undergraduate programs, has been gaining space and prominence in the distance modality, due to socioeconomic aspects that are taken into account by the students. In this scenario, we approach in this research the formative scenario in the state of Pará, Brazil, especially to the natural sciences course and the role of the teacher-tutor, with a view to analyze aspects of teacher training in natural sciences in higher education institutions in the state and the role of the teacher-tutor in this process. In a qualitative research approach, we used the exploratory research regarding objectives and case study regarding the procedures for identifying research indicators. The results were presented in two dimensions: the first one deals with the paraense scenario for teacher training, and in another, it argues the important role of the teacher-tutor who accompanies the student of the natural sciences course throughout the teaching-learning process, ensuring and prioritizing quality in studies in virtual spaces. Therefore, the analyzed data point to the indicators of the process of distance learning in the state and the highlight of the role of teacher-tutor with aspects of pedagogical mediation.
\end{abstract}

Keywords: Distance education; Training scenario; Natural sciences; Teacher-tutor.

\footnotetext{
${ }^{1}$ IFPA - Instituto Federal de Educação, Ciência e Tecnologia do Pará, Parauapebas/PA - Brasil.

2 UFPA/MUSEU GOELDI/EMBRAPA, Programa de Pós-Graduação em Ciências Ambientais, Belém/PA - Brasil.

${ }^{3}$ SEDUC/PA - Secretaria de Estado de Educação do Pará, Belém/PA - Brasil.
} 


\section{INTRODUÇÃO}

No atual panorama de formação docente no Brasil, a educação a distância (EaD) vem ganhando espaço e destaque no cenário educacional. Elementos como a falta de oportunidade de cursar uma graduação no momento adequado, a construção e a organização familiar precoce, situações de pessoas que moram longe de universidades/faculdades, que não dispõem de tempo suficiente para estudar e a inserção de novas tecnologias no mundo da educação são alguns dos fatores que levam o indivíduo a ingressar em cursos de nível superior na modalidade à distância, principalmente na área das licenciaturas plenas.

Não se trata de uma realidade distante nem desconhecida, pois no sentido dessa prática emerge o uso das Tecnologias de Informação e Comunicação (TIC) com a difusão da internet nos âmbitos escolares, surgem os novos procedimentos educativos, a diversidade de metodologias e de práticas pedagógicas capazes de melhorar a educação e fornecer a possibilidade de disseminação do conhecimento.

Nos últimos anos, tem havido um crescente interesse por parte da população em cursar uma graduação, a modalidade de cursos EaD tem ganhado cada vez mais espaço por trazer a oportunidade para aqueles que desejam continuar os seus estudos. Com o avanço da tecnologia veio a oportunidade de levar à educação superior a localidades de difícil acesso, dando a possibilidade de melhorar as condições de vida através da educação para garantir um futuro promissor para aqueles que almejam um mundo mais igualitário.

Segundo Barreto (2007), a modalidade de educação a distância foi organizada para oferecer a oportunidade da população com motivos bem diversificados para que possam cursar o ensino superior com qualidade. A modalidade de ensino EaD apresenta benefícios para a população que antes tinham seu direito restrito à educação por razões diversas como a localização geográfica de difícil acesso e/ou condições financeiras e sociais, dentre outros fatores.

Os cursos de educação à distância surgiram para suprir essa demanda da população que durante muitos anos sentiu a necessidade de estudar, mas não tinha acesso por morar em áreas de difícil acesso ou até mesmo não ter condições de sair de sua localidade e tentar cursar o ensino superior em outra cidade. 0 aumento dos cursos de graduação na área das licenciaturas não veio acompanhando a demanda para atender a todas as regiões do nosso país. A falta de profissionais da educação em diversas disciplinas, a citar as ciências naturais e suas habilitações em biologia, física e química ou a licenciatura específica tem sido um dos enfoques da importância de cursos com modalidade à distância para alcançar e proporcionar a oportunidade de garantir acesso à educação a todos com ensino de qualidade.

Infelizmente no Brasil ainda temos muito a avançar na área da educação para proporcionarmos um ensino de qualidade desde as séries iniciais até o ensino superior. Uma das razões da falta de profissionais na área de educação pode estar relacionada com a dificuldade de ingresso e término dos ensinos fundamental e médio, bem como pela falta de uma base de qualidade que tem dificultado muitos a chegarem ao ensino superior.

Nesse cenário, surge o professor-tutor do curso superior que exerce um papel importante aos cursos EaD, sendo conhecido por diversas formas "tutor", "professor", "facilitador", "orientador", "mediador", "auxiliador" e nesta pesquisa nos apropriamos do termo "professor-tutor" por corroborarmos a sua multifacetada atribuição pedagógica. No latim tutor significa "protector".

Os cursos de modalidade à distância reconhecem a necessidade de ter esses profissionais para acompanhar e comunicar-se com os discentes de forma dinâmica avaliando o seu desenvolvimento durante o curso. 
Atualmente, pouco se sabe sobre a alta competência desses profissionais que atuam como mediadores possuindo requisitos básicos e indispensáveis para exercer essa função pedagógica entre a instituição e os estudantes e/ou entre os professores formadores e os próprios discentes.

Do exposto, emerge como questão de investigação da presente pesquisa buscar respostas ou indícios acerca de saber quais os elementos do cenário formativo docente em ciências naturais das instituições de ensino superior no Pará e da ativa atuação do professor-tutor? Diante dessa problemática, o presente artigo apresenta uma abordagem do cenário educacional e destaca esclarecimentos acerca da importância do professor-tutor no processo, destacando-se as suas atribuições legais, suas dificuldades no processo de ensino-aprendizagem, sua própria formação e, sobretudo, a sua prática docente na formação de novos profissionais da educação no estado do Pará.

Buscando responder tal questionamento, voltamo-nos ao objetivo geral de analisar os aspectos da formação docente em ciências naturais nas instituições de ensino superior no estado do Pará e a atuação do professor-tutor neste processo. Para atender o objetivo proposto, nos apoiamos na pesquisa qualitativa quanto à sua abordagem, exploratória quanto aos objetivos e de estudo de caso quanto aos procedimentos, em virtude de este foco atender como mais especificidade nosso objeto de estudo e possibilitar a nossa inserção no cenário a ser discutido e argumentado.

\section{A EDUCAÇÃO SUPERIOR À DISTÂNCIA NO CENÁRIO BRASILEIRO}

O panorama da Educação Superior no Brasil, na modalidade à distância, vem ganhando um crescente espaço no cenário educacional, devido a algumas estratégias de políticas públicas como o aumento do índice de acesso e do número de vagas a esse nível de ensino, dada a democratização dos meios de comunicação, bem como a busca incessante de mão de obra qualificada frente ao mercado de trabalho cada vez mais competitivo.

A LDB - Lei de Diretrizes e Bases da Educação Nacional (BRASIL, 1996) enuncia em seu Art. 80 que a educação à distância deverá ser uma incentiva do Poder Público, na qual haverá o desenvolvimento e a veiculação de programas de ensino à distância, em todos os níveis e modalidades de ensino. Ainda nesse artigo, a LDB enfatiza que:

$\S 1^{0}$ A educação a distância, organizada com abertura e regime especiais, será oferecida por instituições especificamente credenciadas pela União.

$\S 2^{\circ} \mathrm{A}$ União regulamentará os requisitos para a realização de exames e registro de diplomas relativos a cursos de educação a distância.

$\S 3^{\circ}$ As normas para produção, controle e avaliação de programas de educação a distância e a autorização para sua implementação, caberão aos respectivos sistemas de ensino, podendo haver cooperação e integração entre os diferentes sistemas.

$\S 4^{\circ} \mathrm{A}$ educação a distância gozará de tratamento diferenciado, que incluirá:

I - custos de transmissão reduzidos em canais comerciais de radiodifusão sonora e de sons e imagens;

II - concessão de canais com finalidades exclusivamente educativas;

III - reserva de tempo mínimo, sem ônus para o Poder Público, pelos concessionários de canais comerciais. (BRASIL, 1996) 
É notável a expansão de cursos superiores em todo o território nacional, haja vista a necessidade do incrementar parâmetros educacionais que se caracterizem como uma contribuição para a formação de cidadãos ativos na sociedade e, que estes, sejam capazes de modificar a educação para a sua melhoria.

No cenário da EaD, merece destaque especial a formação inicial de professores de ciências naturais, os quais estão inseridos em um ambiente rico de avanços tecnológicos presentes dentro e fora da sala de aula, o que implica diretamente em suas propostas curriculares e na própria prática docente. As Tecnologias de Informação e Comunicação (TIC's) integraram-se ao meio escolar de certo modo que muitos professores pouco exploraram os seus potenciais educativos para garantir melhores e apropriadas formas de intervenção no processo ensino-aprendizagem.

Os cursos de graduação à distância trazem ao estudante certa autonomia no processo de ensinoaprendizagem, tornando-os sujeitos ativos buscando segundo a sua realidade local. Segundo Nardi et al. (2004) há

\begin{abstract}
abordagens mais amplas das atividades científicas que enfatizem sua importância e suas implicações para a sociedade são cada vez mais necessárias. Por que não colocar os estudantes como sujeitos ativos no processo ensino-aprendizagem? A oportunidade dos estudantes exporem suas ideias, testando seus modelos explicativos, proporciona aos mesmos a organização e a aplicação com responsabilidade dos conhecimentos construídos. (p. 111)
\end{abstract}

Apesar de vivermos na era do avanço tecnológico, muitas pessoas ainda olham para a educação a distância com certa desconfiança, não acreditando muito que possa obter um ensino de qualidade tendo um preconceito com essa modalidade de ensino. Nos últimos anos, a modalidade de ensino a distância tem ganhado mais espaço e tem se destacado pelo seu ótimo desempenho nos cursos de graduação a distância com relação a modalidade de ensino presencial.

Tal prática deixa claro que apesar do ensino ser EaD, os estudantes não deixam de aprender; ao contrário, estes tornam-se sujeitos ativos no processo de ensino-aprendizagem. No Brasil, desde 2005, os cursos a distância têm aumentado a demanda de estudantes, após a regularização do curso a distância pelo Ministério da Educação (MEC), houve uma verdadeira expansão dos cursos que antes se restringe apenas a cursos de especialização passou a ser oferecidos também cursos de graduação em várias universidades em nosso país.

Os cursos EaD alcançam uma clientela bem diversificada por abranger a possibilidade de pessoas de diversas localidades participarem da modalidade de ensino, a ferramenta da tecnologia vem para somar de forma positiva fazendo com que pessoas de diversas regiões consigam interação e construção de conhecimentos através de chats, fóruns de discussões, tornando-os aptos a expor suas ideias de forma interativa, objetiva e discutir sobre diversos assuntos de forma rápida e dinâmica.

Na modalidade de ensino EaD a relação professor-estudante sofreu mudanças de paradigmas com relação à forma de aprender/apreender, pois é oferecido um ensino pautado na autonomia e na capacidade do estudante a buscar, construir ou aprimorar o conhecimento e o professor passa a exercer o papel de mediador, auxiliador, deixando de lado a educação bancária, na qual apenas o professor era o detentor do saber e o estudante apenas receptor. O estudante passa a ocupa o lugar 
de sujeito ativo no processo de ensino-aprendizagem, sendo responsável pela sua autoaprendizagem e aprimoramento de seus conhecimentos prévios, a partir do material didático disponível agindo de forma organizada e com muita disciplina. (IVASHITA \& COELHO, 2009)

O papel do professor na educação a distância deve agir de forma que passa a exerce a função de "provocador" no processo de construção ou aprimoramento do conhecimento levando os estudantes a buscar por mais informações sobre a temática disponibilizada, fazendo com que se perceba a possibilidade de construção de diferentes saberes por sermos seres inacabados e necessitamos de estar em constante buscar do saber. (DIAS \& SILVA, 2005).

De acordo com Chermann \& Bonini (2000, p. 26)

no ensino a distância o estudante é o centro do processo de aprendizagem e deve ser levado a desenvolver habilidades para o trabalho independente, para a tomada de decisões e esforço, auto-responsável; o professor nada mais é que um tutor, um agente facilitador da aprendizagem. Ele, como já vimos, deve desenvolver no estudante a capacidade de selecionar informações, de refletir e decidir por si mesmo. É preciso lembrar que o professor deve ser, antes de mais nada, um eterno estudante, pois não é o dono do conhecimento; ele é, sim, melhor conhecedor dos caminhos que levam a esse conhecimento (p. 26, grifos nossos).

De acordo com Ivashita \& Coelho (2009) na EaD destaca-se a importante função e papel exercido pelo professor-tutor, na modificação de paradigmas da relação professor-estudante, tornando-se claro o real papel desse profissional como um incentivador, colaborador e mediador. É um auxiliador que deve provocar o estudante com recursos disponíveis para buscar sua autonomia no processo de ensino aprendizagem sendo um elo de ligação que aproxima o estudante mais da instituição de ensino e do professor-formador, o professor-tutor faz a ponte para diminuir a distância (ou barreiras) dessa modalidade de ensino, fazendo com que busquem superar suas dificuldades à construção do conhecimento científico.

\section{ENCAMINHAMENTOS METODOLÓGICOS}

Visando buscar respostas para o problema de investigação desta pesquisa, bem como atender o objetivo proposto, ancoramo-nos nos procedimentos metodológicos da pesquisa qualitativa quanto à sua abordagem, por entendermos o nosso papel formativo de investigador em educação em ciências no contexto para o qual estamos imersos. A pesquisa qualitativa permite-nos tratar a investigação de modo a não interferirmos no material obtido para as discussões e, dessa forma, agrega a noção de imparcialidade sobre os dados, apenas nas discussões mostrando os pontos de vistas existentes e as argumentações que são necessárias (TRIVIÑOS, 1987; MINAYO, 2001).

A opção pela pesquisa qualitativa deu-se pelo fato de buscarmos um viés mais amplo de argumentação para que pudéssemos criar um material bem construído e sob o olhar da formação de formadores em licenciatura em ciências naturais, tanto com a habilitação em física, química e biologia, como das pessoas que optam ou fazem tais cursos na modalidade à distância, em virtudes dos aspectos que dirimem esse procedimento para aqueles que não podem fazer o curso regularmente.

Quanto aos objetivos a pesquisa aporta-se como exploratória, por consideramos que o fenômeno investigado possibilita uma aproximação maior e uma familiaridade com a realidade vivenciada na formação docente. A imersão ao explorar a pesquisa, nos conduz a entendermos a situação formativa no estado, em 
múltiplas abordagens e permitir que possamos criar uma visão mais ampla sobre o caso, de modo a estimular a reflexão acerca da formação docente à distância.

Adotamos ainda o estudo de caso como critério de pesquisa, quanto aos procedimentos adotados, uma vez que o cenário explorado direciona ao contexto paraense, para o qual podemos adotá-lo em sua caracterização, expressar opiniões e responder a questão de pesquisa com mais propriedade (YIN, 2001). Exploramos na pesquisa uma maior base na literatura da área, fazendo com que possamos adentrar no cenário investigado, visando sustentar os referencias teórico-metodológicos e mantendo a qualidade da investigação.

Desta forma, elaboramos duas dimensões para discussão dos resultados: de um lado o cenário paraense para a formação de professores no curso de ciências naturais e em suas habilitações; e em outro, o papel importante do professor-tutor que acompanha o estudante em todo o processo de ensino-aprendizagem, garantindo e primando pela qualidade nos estudos em espaços virtuais. A partir deste momento, deter-nos-emos às dimensões supracitadas, para as quais traremos argumentações e uma abordagem discursiva.

\section{DUSCUSSÃO DOS RESULTADOS}

\subsection{A Educação à Distância no estado do Pará: tecendo um panorama acerca das Instituições de Ensino Superior}

O Estado do Pará, em sua totalidade, abrange territórios de difícil acesso, o que dificulta muitos profissionais a se deslocarem a tais regiões para realizar as suas atividades profissionais e ajudar a população que muito precisa. Ao se tratar de formação de professores, temos um aumento considerável na demanda de cursos realizados principalmente pela Universidade do Estado do Pará (UEPA), na Universidade Federal do Pará (UFPA), na Universidade do Sul e Sudeste do Pará (UNIFESSPA), na Universidade Federal do Oeste do Pará (UFOPA) e no Instituto Federal de Educação, Ciência e Tecnologia do Pará (IFPA).

Discorremos aqui apenas sobre as instituições de ensino superior que ofertam cursos grátis para a população, mesmo que conhecendo a realidade das particulares, sabemos que as maiores demandas surgem nas públicas. Tais instituições possuem o intuito de qualificar mão de obra local e intensificar as atividades de ensino e aprendizagem, utilizando os meios midiáticos e dando a oportunidade a quem deseja realmente colaborar com uma educação de qualidade para o Estado e adquirir novos conhecimentos através de uma educação formal.

Na Universidade do Estado do Pará, por meio do o Conselho Universitário, visando envolver o meio social e o educacional em suas propostas de educação superior, principalmente o processo de interiorização, através da Resolução No 211/98 - CONSUN de 26 de junho de 1998 aprova a criação e a implantação do Núcleo de Educação Continuada e a Distância (NECAD), oferecem um suporte tecnológico à tríade ensino, pesquisa e extensão, propiciando uma estrutura qualificada aos cursos realizados no interior do Estado. Nesse âmbito, a UEPA é uma universidade integrada e consorciada com a UNIREDE, Universidade Virtual Pública do Brasil, que busca aliar as universidades amazônicas para compreender "ações voltadas para implantação e implementação de infraestrutura de comunicação, de centro de recursos multimídia e de programas de formação, na modalidade à distância." (PEREIRA et al., 2004, p. 2) 
Atualmente, a UEPA em colaboração com programas governamentais externos oportuniza a muitos a conquista de um curso de nível de superior, em especial as licenciaturas plenas, implantadas em muitos municípios do interior do Estado do Pará, ampliando consideravelmente a oferta do Curso de Ciências Naturais com habilitação em física, química e biologia (e outros cursos de licenciatura). Nesses cursos são utilizados os recursos tecnológicos e as metodologias necessárias para superar alguns empecilhos da educação à distância: o uso de uma plataforma moodle, web e videoconferências, além de recursos humanos como os professores formadores, professores tutorias presenciais e à distância, que possuem o papel de articular e desenvolver uma melhoria na qualidade do processo de aprendizagem do curso.

A Universidade Federal do Pará (UFPA) através da Assessoria de Educação à Distância (AEDI) tem criado estratégias para ampliar e qualificar professores por meio de ações educacionais na região amazônica, atuando em 22 polos, em parcerias com outras instituições de ensino superior e prefeituras locais. Os cursos são ofertados para indivíduos que possuem dificuldades em fazer um curso regular e, agora, tem conseguido ampliar para mais licenciaturas no âmbito formativo e atender municípios distantes da capital, Belém.

A UEPA e UFPA são as instituições que possuem maior demanda de ofertas de cursos no estado do Pará, dada as suas ampliação e quadro de atuação. A UNIFESSPA, a UFOPA e o IFPA ofertam cursos à distância atualmente, mas ainda com poucas demandas ou ainda restritos a cursos como a licenciatura em Pedagogia, com vistas à formação de professores para atuar desde à educação infantil, a assuntos educacionais e de gestão escolar. Acreditamos que dado o potencial de todas as instituições, há uma grande possibilidade de aumento da oferta de cursos, em especial na formação de professores que possam vir atuar e atender as demandas regionais amazônicas.

\subsection{O professor-tutor no cenário formativo da licenciatura em Ciências Naturais: diálogos sobre o seu papel e importância}

Iniciamos com a discussão de Silva et al. (2011) por destacarem que

é indiscutível que na atualidade a modalidade de teleducação está em plena expansão em todo o território brasileiro e quiçá internacionalmente. Esta nova realidade de educação permite uma interação entre o aprendiz e toda a estrutura física, mesmo que estejam separados, ou seja, a comunicação ocorre em um ambiente virtual na maioria das vezes, não deixando de existir, porém o ambiente real, em que atuam os professores, tutores e outros (p.4).

Podemos atribuir o professor-tutor como uma nova categoria docente que se enquadra nos pressupostos pedagógicos de manter e oferecer qualidade aos cursos de educação à distância, em especial das ciências naturais, o qual conduz os acadêmicos ao processo de ensino-aprendizagem, ora como um próprio acadêmico, ora como facilitador/mediador, ora como o próprio professor, sendo necessário também possuir três competências dimensionais na área técnica, gerencial e pedagógica.

Durante muito tempo o papel de professor-tutor e professor-formador tinha funções definidas. O professortutor apenas servia para tirar dúvidas, mas não ensinava sobre nenhum conteúdo. Já o professor-formador era o que detinha a autonomia pedagógica e repassava o conhecimento. Com o avanço das informações e da tecnologia o papel do professor-tutor mudou completamente.

No curso de ciências naturais, o professor-tutor passa a ser orientador, mediador, auxiliador no processo de ensino aprendizagem, ele se torna parceiro dos estudantes para a construção do conhecimento. Segundo 
Figueiredo \& Araújo (2009) o papel do professor-tutor na educação à distância pode ser "caracterizado como um sujeito multifacetado, que possui uma ampla noção do processo de ensino-aprendizagem e enxerga as diversidades e que atua em variadas perspectivas. (p. 3)"

No curso ofertado à distância o professor-tutor exerce a função de facilitador fazendo o intermédio e instruindo de acordo com os recursos disponíveis na sala virtual fornecido pelo professor-formador. Os professores-tutores interagem com estudantes através de recursos como chats e mensagens, fazendo com que o estudante venha a perceber qual o caminho que irá seguir nas atividades propostas nos cursos à distância, podendo dar sugestões de como o estudante poderá abordar e esclarecer as dúvidas existentes e sobre os assuntos abordados no ambiente virtual de forma prestativa e com agilidade.

O estudante do curso de ciências naturais tem disponível uma diversidade de recursos como apoio para seu desenvolvimento acadêmico no processo de construção de conhecimento tendo o professor-formador, tutor presencial e a distância para compreender melhor os assuntos de cada disciplina além dos recursos da sala virtual. (TECCHIO, 2008).

Para o curso, o professor-tutor deve estabelecer uma ponte que faz a interlocução dos conhecimentos necessários ao processo de ensino-aprendizagem, deve anular o conceito que somente ele tem de ser o detentor do conhecimento e que o estudante é apenas um mero receptor, sem poder haver uma troca mútua de informações na aprendizagem. O estudante torna-se sujeito social, histórico e cultural ativo na construção de seu próprio conhecimento, fazendo assim que ocorra a troca de conhecimento e haja a interação o aproximando da instituição de ensino ao esclarecer dúvidas, motivar, auxiliar, mediar, administrar, instruir, interagir e avaliar. (WEIDUSCHAT, 2003)

Com base nesses elementos citados, o professor-tutor deve agir respeitando a autonomia de cada estudante no processo de ensino-aprendizagem em ciências naturais, não deixando de orientar e supervisionar, de modo a garantir uma educação de qualidade sempre promovendo a participação dos estudantes nas atividades disponibilizadas nos cursos EaD, bem como deve vir a estimulá-lo na busca pelo saber. (BATTISTI et al., 2010).

Outro requisito básico para o curso e que marca a atuação do professor-tutor ao exercer seu papel é o de comunicador, deve-se à interação direta e indireta, fazendo uma ponte de ligação que percorre vários caminhos aproximando por exemplo os estudantes da instituição de ensino, da sala de aula mesmo em espaço virtual as tecnologias soma-se na contribuição da construção de conhecimento vindo enriquecer e diminuir a distância do espaço geográfico existente entre ambos, principalmente no contexto paraense.

Esse profissional torna-se de suma importância por ele não atuar de forma isolada e sim com a colaboração de toda uma equipe de profissionais que em conjunto procuram passar o que há de melhor para o sucesso no processo de ensino-aprendizagem, agindo com muita responsabilidade e atenção estando sempre disposto a ajudar e motivar quando necessário de forma que venha tentar resgatar os estudantes que não estão interagindo nas disciplinas do curso de ciências naturais. (BATTISTI, 2010).

O diálogo torna-se algo muito importante na modalidade de ensino à distância visto que para o processo de ensino aprendizagem ocorrer de forma eficaz o professor-formador, o professor-tutor e o estudante necessitam estar em constante diálogo, as ferramentas disponibilizadas vem para somar e ajudar na interação para uma reflexão conjunta sobre os conteúdos estudados durante a aprendizagem científica e formativa do curso. 
O diálogo é bastante utilizado para minimizar a distância e as dificuldades de um ensino que instiga a capacidade do estudante a autoaprendizagem nas ciências. No ensino EaD, a ferramenta do diálogo é usada constantemente durante todo o processo, visto que a transmissão do conhecimento e a seu aprimoramento não se constroem sozinhos, de forma isolada; necessita de uma ação reflexiva de duas ou mais pessoas. (MANARA \& FREITAS, 1998).

Nesse sentido, o professor-tutor torna-se protagonista no processo de ensino-aprendizagem do curso de ciências naturais, por atuar fazendo um elo de ligação entre estudante, professor-formador e tutor e a instituição de ensino. A função do professor-tutor permite está em contato direto com o estudante graças ao avanço das tecnologias, ao diálogo constante tende a minimizar as dificuldades encontradas na compreensão dos conteúdos proposto. Essa modalidade de ensino busca propor uma educação com total liberdade, porém requer disciplina por parte dos estudantes por fomentar a autoconstrução de conhecimento. (FURQUIM, 2012)

\section{CONSIDERAÇÕES FINAIS}

A modalidade de educação à distância vem quebrando um paradigma no ensino de licenciaturas, visto que boa parte dos professores que atuam na educação básica não dispõe muito de conhecimentos na área da informática, ou não se sentem muito à vontade diante das novas tecnologias que são apresentadas a cada dia. A necessidade de esses profissionais buscarem cursos de aperfeiçoamento para melhorar o processo de ensino-aprendizagem tem levado muitos profissionais a buscarem cursos de modalidade à distância.

Tal necessidade emergente faz com que eles comecem a aprimorar seus conhecimentos e melhorar o seu desempenho na utilização das novas tecnologias ao se matricularem em cursos à distância passam a utilizar melhor as ferramentas tecnológicas, deixando-os mais livres na utilização de recursos de multimídia durante as aulas, tornando-as mais dinâmicas, interativas e enriquecidas com recursos que desperta cada vez mais o interesse dos estudantes.

Na presente pesquisa apontamos evidências acerca da educação à distância no contexto paraense por ter ganhado cada vez mais espaço destacando-se no cenário educacional como uma forma de ensino que proporciona a autoaprendizagem dos estudantes e na formação de professores de ciências naturais. Através da mediação de recursos didáticos disponíveis na sala virtual e a participação de profissionais, destacamos ser de extrema importância no ensino EaD o papel do professor-tutor por mediar a construção do conhecimento.

Neste contexto, aferimos que o objetivo de pesquisa foi atendido conforme a demanda direcionada pela questão de investigação que foi norteadora para o processo de pesquisar a temática. Além disso, foi possível identificar as diferentes concepções sobre qual o papel exercido pelo professor-tutor na formação de professores de ciências naturais, no qual foram destacados como o de mediador, facilitador, instrutor, intermediador de conhecimento, auxiliador de aprendizagem, esclarecedor de dúvidas, administrador, motivador, avaliador, dentro outros, dada a sua atribuição multifacetada.

A função educativa do professor-tutor emerge no cenário paraense e no contexto da licenciatura em ciências naturais para somar de forma positiva, trazendo consigo uma quebra de paradigmas na forma de ensino totalmente autônomo, uma vez que antes era centralizado em salas de aulas convencionais e que o professor exercia o papel de forma ativa na transmissão de conhecimento e os estudantes 
apenas recebiam as informações repassadas pelo professor agindo no processo de ensino de forma passiva. Portanto, tais considerações vêm reafirmar a importância da figura do professor-tutor na aproximação dos estudantes com a construção do conhecimento científico.

\section{REFERÊNCIAS}

BARRETO, Lina Sandra. Educação à distância: perspectiva histórica. Disponível em < http://www.abmes.org.br/abmes/public/arquivos/publicacoes/Estudos26.pdf >. Acesso em 10 de abril de 2013.

BATTISTI, P.; CARDOSO, J. M. R.; MOREIRA, B. C. de M.; KLAES, L. S.; DALMAU, M. B.; SAFANELLI, L. S. A interação tutor a distância e aluno no processo ensino-aprendizagem. In: X COLóQUIO INTERNACIONAL SOBRE GESTIÓN UNIVERSITARIA EM AMERICA DEL SUR. Mar Del Plata, 8 a 10 de dezembro de 2010.

BRASIL. Lei de Diretrizes e Bases da Educação Nacional: Lei no 9394/96. Ministério da Educação. Brasília: 1996.

BRASIL. Referenciais de Qualidade para a Educação Superior a Distância. Ministério da Educação. Secretaria de Educação a Distância. Brasília: 2007.

CHERMANN, Maurício; BONINI, Luci Mendes. Educação a distância. Novas tecnologias em ambientes de aprendizagem pela Internet. Universidade Braz Cubas, s/d (2000?).

DIAS, Sanda Silva; SILVA, Marco. Dialógica e Interatividade em educação on-line. Revista FAEEBA

- Educação e Contemporaneidade, v. 14, n. 23, 169-179, 2005.

FIGUEIREDO, Lílian Kelly de Almeida; ARAÚJO, Rosana Sarita de Araújo. Educação a Distância Online e o Papel do Tutor. In: 150 CONGRESSO INTERNACIONAL ABED DE EDUCAÇÃO A DISTÂNCIA, Fortaleza, 27 a 30 de setembro de 2009.

FURQUIM, Alexandra Silva dos Santos. A tutoria na educação a distância: um estudo sobre o papel de tutores à distância. In: XVI JORNADA NACIONAL DA EDUCAÇÃO. UNIFRA, de 20 a 24 de agosto de 2012.

IVASHITA, Simone Burioli; COELHO, Marcos Pereira. Ead: o importante papel do professor-tutor. In: IX Congresso Nacional de Educação - EDUCERE III - Encontro Sul Brasileiro de Psicopedagogia. Pontifícia Universidade Católica do Paraná - Câmpus Curitiba, 2009.

MANARA, Alecia Saldanha; FREITAS, Indiara. O trabalho docente do professor tutor na educação à distância. $\quad 1998 . \quad$ Disponível http://www.unisc.br/portal/upload/com arquivo/o trabalho docente do professor tutor na educa acaao aa distaancia.pdf. Acesso em 12 de abril de 2019.

MINAYO, M. C. S. (Org.). Pesquisa social: teoria, método e criatividade. Petrópolis: Vozes, 2001.

NARDI, Roberto; BASTOS, Fernando; DINIZ, Renato Eugênio da Silva. Pesquisas em ensino de ciências: contribuições para a formação de professores. 5a Ed. São Paulo: Escrituras, 2004.

PEREIRA, Denise C. Miranda; SILVA, José Roberto Alves; LIMA, Rita de C. da C. Educação a Distância: o pedagogo produzindo material didático. Projeto de Ensino. Universidade do Estado do Pará, 2004.2 Disponível em 
<http://www.aunirede.org.br/portal/Arquivos/Informe/Artigos/Pedagogo produzindo.pdf $>$. Acesso em 08 jan. de 2019.

SILVA, Ari Gonçalves; ANDRADE, Luci Carlos; SILVA, Milene Bartolomei. Educação a distância: as novas tecnologias e o papel do tutor na perspectiva da construção do conhecimento. In: XVII CONGRESSO DE EDUCAÇÃO À DISTÂNCIA. Manaus, de 30 de agosto a 02 de setembro de 2011.

TECCHIO, Edivandro Luiz; DALMAU, Marcos Baptista Lopes; MORETTO, Simone Machado; NUNES, Thiago Soares; MELO, Pedro Antônio. Competências fundamentais ao tutor de ensino a distância. In: XIV CONGRESSO INTERNACIONAL ABED DE EDUCAÇÃO A DISTÂNCIA. Santos / SP, de 14 a 17 de setembro de 2008.

WEIDUSCHAT, Iris. O papel da tutoria na ead: organizar e dirigir situações de aprendizagem. In: $\mathbf{X}$ CONGRESSO INTERNACIONAL ABED DE EDUCAÇÃO A DISTÂNCIA. Porto Alegre, de 1 a 3 de outubro de 2003.

TRIVIÑOS, A. N. S. Introdução à pesquisa em ciências sociais: a pesquisa qualitativa em educação. São Paulo: Atlas, 1987.

YIN, R. K. Estudo de caso: planejamento e métodos. Trad. de Daniel Grassi. Porto Alegre: Bookman, 2001. 